\title{
Spinal inhibition of p38 MAP kinase reduces inflammatory and neuropathic pain in male but not female mice: sex-dependent microglial signaling in the spinal cord
}

Sarah Taves ${ }^{1,2,4}$, Temugin Berta ${ }^{1,4}$, Da-Lu Liu ${ }^{1}$, Sophie Gan ${ }^{1}$, Gang Chen ${ }^{1}$, Yong Ho Kim ${ }^{1}$, Thomas Van de Ven ${ }^{1}$, Stefan Laufer ${ }^{3}$, Ru-Rong Ji ${ }^{1,2}$

${ }^{1}$ Department of Anesthesiology, Duke University Medical Center, 595 LaSalle Street, Durham, NC 27710, USA

${ }^{2}$ Department of Neurobiology, Duke University Medical Center, 595 LaSalle Street, Durham, NC 27710, USA

${ }^{3}$ Departments Pharmacy and Biochemistry, University of Tuebingen, Auf der Morgenstelle 8, 72076 Tuebingen, Germany

${ }^{4}$ These authors contribute equally to this study 


\begin{abstract}
Previous studies have shown that activation of p38 mitogen-activating kinase (MAPK) in spinal microglia participates in the generation of inflammatory and neuropathic pain in various rodent models. However, these studies focused on male mice to avoid confounding effects of the estrous cycle of females. Recent studies have shown that some spinal pro-inflammatory signaling such as Toll-like receptor 4-mediated signaling contributes to pain hypersensitivity only in male mice. In this study we investigated the distinct role of spinal p38 in inflammatory and neuropathic pain using a highly selective p38 inhibitor skepinone. Intrathecal injection of skepinone prevented formalin induced inflammatory pain in male but not female mice. Furthermore, intrathecal skepinone reduced chronic constriction injury (CCI) induced neuropathic pain (mechanical allodynia) in male mice on CCI-day 7 but not CCI-day 21. This male-dependent inhibition of neuropathic pain also occurred in rats following intrathecal skepinone. Nerve injury induced spinal p38 activation (phosphorylation) in CX3CR1-GFP ${ }^{+}$microglia on CCI-day 7, and this activation was more prominent in male mice. In contrast, CCI induced comparable microgliosis and expression of the microglial markers CX3CR1 and IBA-1 in both sexes. Notably, intraperitoneal or local perineural administration of skepinone inhibited CCI-induced mechanical allodynia in both sexes of mice. Finally, skepinone only reduced the frequency of spontaneous excitatory postsynaptic currents (sEPSCs) in lamina IIo neurons of spinal cord slices of males 7 days post CCI. Therefore, the sex-specific p38 activation and signaling is confined to the spinal cord in inflammatory and neuropathic pain conditions.
\end{abstract}

Keywords: microglia, p38, MAPK, neuropathic pain, inflammatory pain, male, sex 


\section{Introduction.}

Chronic pain conditions are not evenly distributed through the population but occur more frequently in the elderly and in women (Pleis et al., 2010). Of particular concern, women are more sensitive to painful stimuli than their male counterparts and are more often undertreated for their pain (Mogil, 2012). Despite the increased incidence of chronic pain in women and the fact that clinical trials must incorporate woman into trial design, the vast majority of basic science research uses male subjects exclusively (Mogil and Chanda, 2005) citing that gender differences may be attributable to higher order social factors; factors that are difficult to study in animal models.

Microglial cells in the spinal cord are known to play a role in the development of chronic pain (Tsuda et al., 2005;Ji et al., 2013;Milligan and Watkins, 2009;Calvo and Bennett, 2012). In male rodents, inhibition of spinal microglial activation with minocycline can attenuate the earlyphase development of neuropathic pain as well as inflammatory pain in rodents (Cho et al., 2006;Ledeboer et al., 2005;Berta et al., 2014;Hua et al., 2005). In females, minocycline is ineffective in reducing pain behavior following spared nerve injury (Sorge et al., 2015), yet effective following spinal cord injury (Chen et al., 2012). Recently, minocycline was also shown to reduce the maintenance phase of cancer pain in female Wistar rats (Yang et al., 2015). Thus, the contribution of microglial activation in females may be model dependent.

Previous studies from our lab and many other labs show that activation of p38 mitogenactivated protein kinase (MAPK) in spinal microglia contributes to the generation of neuropathic pain, postoperative pain, as well as opioid-induced tolerance in male rodents (Jin et al., 2003; Tsuda et al., 2004;Cui et al., 2006;Kobayashi et al., 2008;Hains and Waxman, 2006;Wen et al., 2009). Spinal p38 has also been implicated in the generation of formalin-induced acute inflammatory pain (Svensson et al., 2005). Mechanistically, activation of p38 in microglia results in increased synthesis of pro-inflammatory cytokines such as TNF- $\alpha$, IL-1 $\beta$, and IL-6 (Xu et al., 2013a;Ji and Suter, 2007;Clark et al., 2006;Berta et al., 2014). These cytokines play a critical

role in inducing hyperactivity of dorsal horn neurons resulting in pain hypersensitivity (Kawasaki et al., 2008;Ren and Torres, 2009;Zhang et al., 2010;Park et al., 2011;Yan and Weng, 2013; Chirila et al., 2014). Microglial activation was thought to play a role in both sexes (Chen et 
al., 2012; Cho et al., 2006;Ledeboer et al., 2005), however, it is incompletely known whether p38 signaling in microglia is sex-dependent. In this study we examined whether there is sex-specific activation and signaling of $\mathrm{p} 38$ in persistent pain conditions. Our data show that 1) nerve injury primarily activates p38 in the spinal cord of male mice and 2) intrathecal injection of a selective p38 inhibitor skepinone reduced neuropathic pain in male but not female rodents.

\section{Materials and Methods}

\subsection{Animals and neuropathic and inflammatory pain models}

Male and female wild-type CD1 mice (8-10 week old) as well as male and female Sprague Dawley rats (8-10 week old) were purchased from Charles River Laboratories. CX3CR1-GFP mice on a C57BL/6 background were purchased from Jackson Laboratory and bred in-house at GSRB2 Animal Facility of Duke University Medical Center. All the animal procedures were approved by the Animal Care Committee of Duke University Medical Center. To produce chronic constriction injury $(\mathrm{CCI})$ in mice, the left sciatic nerve was exposed at mid-thigh level under isoflurane anesthesia, and 3 loose silk ligatures (number 6 suture) approximately $1 \mathrm{~mm}$ apart were tied around the sciatic nerve and the incision was closed with sutures (Chen et al., 2014). CCI was also produced in rats with 4 loose ligatures as originally reported (Bennett and Xie, 1988). The ligatures were loosely tied until a flinch of the ipsilateral hind limb was observed. To produce inflammatory pain in mice a solution of $5 \%$ formalin $(20 \mu \mathrm{l})$ was administered by intraplantar injection under the skin of the left hind paw. Control animals received the same volume of sterile saline solution.

\subsection{Drugs and administration}

The p38 inhibitor skepinone (a gift from Stephan Laufer's laboratory) as previously reported (Koeberle et al., 2012), was dissolved in DMSO and subsequently diluted in sterile saline. The final DMSO concentration was $10 \%$. The p38 inhibitor, 4-(4-fluorophenyl)-2-(4methylsulfonylphenyl)-5-(4-pyridyl)-1H-imidazole (SB203580) was obtained from Calbiochem (LaJolla, CA) and diluted in sterile saline. For intraperitoneal (IP) injection, the drug was 
injected into the peritoneal cavity using a 30G needle. For intrathecal (IT) injection, animal was briefly anesthetized with isoflurane and a spinal cord puncture was made with a $30 \mathrm{G}$ needle between the L5 and L6 level to deliver reagents ( $10 \mu \mathrm{l}$ for mice and $20 \mu \mathrm{l}$ for rats) to the cerebral spinal fluid (Hylden and Wilcox, 1980). For perineural injection, while under isoflurane anesthesia the sciatic nerve was exposed just above the level of the CCI surgery and drug or vehicle $(6 \mu \mathrm{L})$ was carefully injected into the perineural space using a $30 \mathrm{G}$ needle connected to a syringe via flexible tubing (Berta et al., 2014).

\subsection{Immunohistochemistry}

Mice were terminally anesthetized with isoflurane and perfused transcardially with $4 \%$ paraformaldehyde in PBS. The spinal cord L4-L5 segments were dissected, postfixed in the same fixative overnight at $4{ }^{\circ} \mathrm{C}$, and then transferred to $30 \%$ sucrose overnight. The transverse spinal cord sections $(20 \mu \mathrm{m})$ were cut in a cryostat. These sections were blocked for $30 \mathrm{~min}$ at room temperature in a solution containing $10 \%$ normal donkey serum and $0.5 \%$ Triton X-100, and incubated overnight at $4{ }^{\circ} \mathrm{C}$ with primary antibodies against IBA-1 (1:1000, rabbit; Wako), and phosphorylated-p38 (1:500, rabbit; Cell Signaling). The sections were then incubated by fluorescent-conjugated secondary antibodies (1:250, Jackson Immunoresearch). After immunolabeling, some sections were counterstained with DAPI (1:5000, Invitrogen) for $10 \mathrm{~min}$ at room temperature to label all spinal nuclei. Finally, all the slides were mounted with coverslips. Immunohistochemical staining was quantified by either fluorescent intensity or by the number of positive cells. Staining was viewed on a Nikon microscope. Fluorescent intensity was measured from the entire dorsal horn region on either the contralateral or ipsilateral side of the L4-L5 spinal cord. The number of positive cells or intensity of immunofluorescence was calculated by a blinded observer from a square region (medial laminae I-III) of either the contralateral or ipsilateral side of the L4-L5 spinal cord of both sexes. The region remained consistent between sections.

\subsection{Western Blotting}

As we reported previously (Berta et al., 2014), lumbar spinal cord dorsal horn tissues were homogenized in a RIPA lysis buffer (10x, Millipore) containing protease and phosphatase inhibitors. Protein concentrations were determined by BCA Protein Assay (Pierce). Thirty 
micrograms of protein were loaded for each lane and separated by SDS-PAGE gel (4-15\%; Bio$\mathrm{Rad})$. After the transfer, the blots were incubated overnight at $4{ }^{\circ} \mathrm{C}$ with polyclonal antibody against p-p38 (1:500, rabbit; Cell Signaling) or p38 (1:1000, rabbit; Cell Signaling). For loading control, the blots were probed with GAPDH antibody (1:20,000, mouse; Millipore). These blots were further incubated with horseradish peroxidase-conjugated secondary antibody (1:2000, GE Healthcare) developed in ECL solution (Thermo), and exposed onto ChemiDoc ${ }^{\mathrm{TM}}$ MP Imaging System (Bio-Rad) for 1-10 min. Specific bands were evaluated by apparent molecular size. The intensity of the selected bands was analyzed using NIH Image J software.

\subsection{Behavioral analysis}

Animals were placed in boxes on an elevated metal mesh floor and allowed to habituate for at least 2 days before baseline testing and prior to each examination. Room temperature and humidity remained stable for all experiments. For testing inflammatory pain following formalin injection, spontaneous pain behavior was recorded on video and scored in five minute increments for the time (seconds) that the animals spent licking, biting or guarding the injected paw. Following CCI, the plantar surface of each hindpaw was stimulated with a series of von Frey hairs with logarithmically increasing stiffness $(0.02-2.56 \mathrm{~g}$ for mice and $0.02-15 \mathrm{~g}$ for rats, Stoelting), presented perpendicular to the plantar surface. Based on Dixon's up-down method (Dixon, 1980), six von-Frey applications were presented after crossing threshold in order to calculate the $50 \%$ paw withdrawal threshold. The frequency response was determined by stimulating the hindpaw with the 0.6 gram von Frey hair ten times and recording the number of withdrawals. All behavioral scoring was performed blinded to treatment.

\subsection{Patch clamp recordings in spinal cord slices}

As we previously reported (Chen et al., 2014), a portion of the lumbar spinal cord (L4-L5) was removed from young mice (4-6 weeks old of both sexes, 7 days after CCI surgery) under urethane anesthesia (1.5-2.0 g/kg, i.p.) and kept in preoxygenated ice-cold Krebs' solution. Transverse slices $(400-600 \mu \mathrm{m})$ were cut on a vibrating microslicer. The slices were perfused with Krebs' solution $(8-10 \mathrm{ml} / \mathrm{min})$ that was saturated with $95 \% \mathrm{O} 2$ and $5 \% \mathrm{CO} 2$ at $36{ }^{\circ} \mathrm{C}$ for at least 1-3 h before experiment. The Krebs' solution contains (in $\mathrm{mM}$ ): $117 \mathrm{NaCl}, 3.6 \mathrm{KCl}, 2.5$ 
$\mathrm{CaCl} 2,1.2 \mathrm{MgCl} 2,1.2 \mathrm{NaH} 2 \mathrm{PO} 4,25 \mathrm{NaHCO} 3$, and 11 glucose. The whole-cell patch-clamp recordings were made from outer lamina II (lamina IIo) neurons in voltage-clamp mode. Patch pipettes were fabricated from thin-walled, borosilicate, glass-capillary tubing $(1.5 \mathrm{~mm}$ outer diameter, World Precision Instruments). After establishing the whole-cell configuration, neurons were held at the potential of $-70 \mathrm{mV}$ to record sEPSCs. The resistance of a typical patch pipette is $5-10 \mathrm{M}$. The internal solution contains (in $\mathrm{mM}$ ): 135 potassium gluconate, $5 \mathrm{KCl}, 0.5 \mathrm{CaCl}$, $2 \mathrm{MgCl}$, 5 EGTA, 5 HEPES, 5 ATP-Mg. Membrane currents were amplified with an Axopatch 200B amplifier (Molecular Devices) in voltage-clamp mode. Signals were filtered at $2 \mathrm{kHz}$ and digitized at $5 \mathrm{kHz}$. Data were stored with a personal computer using pCLAMP 10 software and analyzed with Mini Analysis (Synaptosoft Inc.)

\subsection{Statistics}

All data were expressed as mean \pm s.e.m. Differences between groups were compared using twotailed Student $t$-test, One-Way ANOVA, or Two-Way ANOVA with repeated measures, followed by Bonferroni's test (Prism 4). The criterion for statistical significance was $P<0.05$.

\section{Results}

\subsection{Intrathecal administration of skepinone reduces inflammatory pain in male but not female} mice

To test the sex-dependent role of spinal p38 in inflammatory pain, male and female mice were administered $30 \mu \mathrm{g}$ of the $\mathrm{p} 38$ inhibitor skepinone via intrathecal route (IT) 30 minutes prior to the injection of formalin in the hind paw. The time spent licking, biting, or guarding the injected paw was monitored and recorded in 5 min bins. Data is also presented as phase I (0-10 minutes) and phase II (15-45 minutes following formalin injection) behavior. Phase I behavior is known to depend on peripheral nerve activity while phase II behavior is dependent on central sensitization (Dickenson and Sullivan, 1987;Ji et al., 1999). Following formalin administration we found the typical pattern of spontaneous pain behavior in vehicle (10\% DMSO) treated males and females, showing a biphasic response, with the first peak around $5 \mathrm{~min}$ post-formalin administration and a 
second wider peak around 25 minutes post-formalin administration (Fig. 1A-C). We found no sex differences in both phase I and phase II responses in vehicle-treated males and females (Fig. 1A-C). Strikingly, IT skepinone administration (30 and $60 \mu \mathrm{g}$ ) significantly reduced the phase II spontaneous pain behavior of males but not female mice (Fig. 1A-C), and two-way ANOVA revealed a significant effect of drug treatment in males $\left(F_{(2,12)}=10.73, P=0.0021\right.$, Figure 1A) but not females $\left(\mathrm{F}_{(2,12)}=0.03, P=0.9704\right.$, Fig. 1B). IT skepinone (30 and $\left.60 \mu \mathrm{g}\right)$ had no effects on phase I spontaneous pain in both sexes (Fig. 1A-C). These results imply that IT administration of the p38 inhibitor reduced pain behavior by inhibiting central mechanisms of pain sensitization only in male mice. Since skepinone can penetrate the brain-blood barrier (Koeberle et al., 2012), similar sex-dependent results were seen when skepinone (30 mg/kg) was administered systemically via intraperitoneal (IP) injection one-hour prior to intraplantar formalin injection (Figure 1 D-E). Two-way ANOVA of Phase II response revealed a significant effect of sex in skepinone treated animals $\left(F_{(1,14)}=4.62 p=0.0495\right.$, Fig. 1D).

\subsection{Intrathecal p38 inhibitors reduce CCI-induced mechanical allodynia in males in early phase}

Activation of p38 MAPK is a key signaling event in the development of neuropathic pain in male rodents (Ji et al., 2009;Jin et al., 2003;Tsuda et al., 2004). However, it is incompletely known whether p38 signaling participates in the development of neuropathic pain in females. We performed chronic constriction injury (CCI) of the sciatic nerve to induce neuropathic pain and delivered IT skepinone (30 $\mu \mathrm{g}$ per mouse) to male and female mice seven days post-injury. We monitored mechanical allodynia using von Frey hairs to determine the paw withdrawal threshold. Both male and female mice developed robust mechanical allodynia 7-days following CCI, however, spinal inhibition of p38 significantly reduced neuropathic pain behavior only in male and not female mice (Fig. 2 A). Two-way ANOVA revealed a significant effect of sex in skepinone treated mice post-injection $\left(\mathrm{F}_{(1,10)}=9.87, P=0.0105\right.$, Fig. $\left.2 \mathrm{~A}\right)$. This male-specific effect in neuropathic pain was confirmed using the classic p38 inhibitor SB203580 (Sorge et al., 2015), which has been widely used in previous studies on neuropathic pain and inflammatory pain (Jin et al., 2003b; Tsuda et al., 2004;Svensson et al., 2003). IT injection of SB203580 (30 $\mu \mathrm{g}$ per mouse) 7-days following nerve injury also produced a temporary inhibition of mechanical allodynia in male but not female mice (Sorge et al., 2015). In contrast, IT injection of skepinone (30 $\mu \mathrm{g}$ per mouse) in a late phase of neuropathic pain (21-days post CCI) failed to reduce nerve 
injury-induced mechanical allodynia in male and female mice (Fig. 2B), indicating a predominant role of microglial p38 signaling in the development of neuropathic pain in the CCI model.

In order to establish the scope of this finding we also performed cross-species experiments in rats. We performed CCI in adult male and female rats and found that both sexes developed robust allodynia 7-days post-CCI and that administration of IT skepinone (60 $\mu \mathrm{g}$ per rat, $20 \mu \mathrm{l}$ ) significantly reduced neuropathic pain behavior only in male rats and had no effect in females (Fig. 2C).

Next, we used systemic administration by IP injection to determine if the sex-dependent effects of p38 inhibition were confined to the spinal cord or persisted throughout the body. In contrast to the formalin model, IP administration of skepinone seven days post-CCI produced a sex-independent reduction in neuropathic pain behavior: mechanical allodynia was similarly reduced in both male and female mice by systemic p38 inhibition (Fig. 3A). Two-way ANOVA found no effect of sex in skepinone treated animals. $\left(\mathrm{F}_{(2,20)}=0.36, P=0.7031\right.$, Fig. 3A $)$.

Due to the high degree of blood-brain barrier permeability of skepinone the effectiveness of systemic skepinone administration in females could be mediated in the periphery or in higher level brain regions involved in pain. To address this issue we performed local perineural injection of skepinone (18 $\mu \mathrm{g}$ per mouse) into the perineural space just proximal to the CCI ligatures 7 days post-injury. We monitored paw withdrawal threshold following the injection. Measurements taken prior to six hours after injection were deemed unreliable as both vehicle controls and treated animals had elevated levels of pain behavior likely due to the perineural injection itself. At six hours post-skepinone treatment both male and female mice displayed increased paw withdrawal thresholds. Two-way ANOVA found no effect of sex in skepinone treated animals $\left(\mathrm{F}_{(3,36)}=0.21, P=0.8910\right.$, Fig. 3B). Remarkably, the reduction in pain behavior was persistent for several days post-treatment (Fig. 3B), whereas the reduction in pain behavior seen after intrathecal treatment peaked around three hours post-treatment and dramatically declined after 6 hours post-injection (Fig. 2).

\subsection{CCI induces comparable microglial reaction in the spinal cord of both sexes}


Next we wanted to ascertain whether microglial cells were being activated in both sexes. We used the most common marker of microglial activation IBA-1 to revel changes in cell morphology and proliferation of microglia (Echeverry et al., 2008;Beggs and Salter, 2007). We performed IBA-1 immunohistochemistry on lumbar spinal cord sections from male and female mice 7 days post-CCI. We found that both males and females displayed remarkable changes in microglial morphology, as revealed by increases in staining intensity and cell number in the dorsal horn ipsilateral to injury (Fig. 4). However, no difference between males and females was found in IBA-1 staining intensity and number of IBA-1 labeled microglial cells (Fig. 4). We concluded that microglial cells are similarly activated in the spinal cord of both males and females following nerve injury at the time point we examined.

\subsection{CCI induces more profound p38 activation in spinal microglia of male mice}

To determine if p38 MAPK was being activated by CCI we performed western blot for phosphorylated p38 (p-p38) on ipsilateral and contralateral dorsal horn tissue from mice 7 days post-injury. We found that activation of p38 is sex-dependent. There were significant increases in p-p38 and p38 levels only in male ipsilateral dorsal horn (Fig. 5 A-D). However, we failed to see significant p38 and p-p38 increases in female spinal cord dorsal horn (Fig. 5 A-D). There was additional p-p38 increase in male dorsal horn of CCI-7d mice when normalized with the corresponding p38 expression $(P<0.05$, Student t-test, Fig. 5E), indicating that p-p38 increase in males is not totally dependent on p38 increase. Although the increase in ipsilateral dorsal horn of female mice was not significant $(P>0.05$, Student t-test), female mice showed a trend of increase in p-p38 and p38 levels on CCI-7d (Fig. 5C,D).

Next we tested whether p-p38 was elevated specifically in microglia using transgenic mice expressing GFP under the $C x 3 c r l$ promoter, which is microglial specific in the central nervous system (Taves et al., 2013). Seven days post-CCI we obtained lumbar spinal cord tissue from CX3CR1-GFP mice and performed immunohistochemistry for p-p38. Similar to IBA-1 staining for microglia we saw an increased GFP fluorescence and proliferation of GFP-positive microglial cells in both male and female ipsilateral dorsal horn (Fig. 6A,B and Fig. 7A). The pp38 staining (red fluorescence) colocalized specifically with the GFP (green) marker in

microglial cells on the ipsilateral side of spinal cord 7 days post CCI (Fig. 6A,B). We counted 
1142 p-p38-positve cells from 9 mice (714 from 5 males and 428 from 4 females) and found that 98.4\% and $98.7 \%$ of p-p38-positive cells also expressed CX3CR1-GFP in spinal cord of males and females, respectively.

We found increases in the numbers of p-p38 positive cells in the ipsilateral dorsal horn $(P<0.05$, Student t-test, vs. the contralateral) in both male and female mice (Fig. 6A,B and Fig. 7B). However, male mice showed stronger immunofluorescence of p-p38 staining in the dorsal horn compared to female mice ( $P<0.05$, Student t-test, Fig. 7C). Together, our western blot and immunostaining results indicate that nerve injury activates p38 in spinal microglia primarily in male mice.

3.5. CCI-induced enhancement of synaptic transmission in spinal cord neurons is suppressed by p38 inhibition in male but not female mice.

Nerve injury-induced synaptic plasticity in spinal cord pain circuit has been implicated in the genesis of neuropathic pain (Xu et al., 2013b). We have previously shown that CCI induced significant increases in both frequency and amplitude of spontaneous excitatory postsynaptic currents (sEPSCs) in lamina IIo neurons of spinal cord slices (Xu et al., 2013b). Thus, we also performed patch clamp recordings in lamina IIo neurons of spinal cord slices of 7d-CCI mice from both sexes and tested the effects of skepinone on the sEPSCs. We found that superfusion of skepinone $(3 \mu \mathrm{M})$ in lumbar spinal cord slices suppressed sEPSC frequency in IIo neurons of males but not females (Fig. 8A,B). Skepinone had no effects of sEPSCs amplitude in both sexes, indicating possible presynaptic effects of p38 in synaptic transmission.

\section{Discussion}

\subsection{Sex dependent and independent changes in spinal cord microglia after nerve injury}

Only certain microglial changes contribute to enhanced pain states (Ji et al., 2013). Nerve injury induces marked morphological changes of spinal microglia (microgliosis) and also causes 
profound microglial proliferation (Echeverry et al., 2008;Beggs and Salter, 2007;Suter et al., 2007;Zhang et al., 2007). Accumulating evidence suggests that the reactive changes of microglia (gliosis and proliferation) can be dissociated from pain states (Tsuda et al., 2003;Colburn et al., 1997;Zhang et al., 2012; Ji et al., 2013). CCI induced comparable morphological changes and proliferation in both sexes, as illustrated by IBA-1 immunostaining (Fig. 4), which is supported by a recent study in the spared nerve injury model (Sorge et al., 2015). However, intrathecal injection of microglial inhibitor minocycline, microglial signaling inhibitor (P2X4 or p38 inhibitor) and microglial toxin only suppressed SNI-induced neuropathic pain in male mice (Sorge et al., 2015). Similarly, intrathecal activation of microglia via Toll-like receptor 4 agonist lipopolysaccharide elicits pain only in males (Sorge et al., 2011). The chemokine receptor CX3CR1 is induced in spinal microglia after nerve injury and contributes to neuropathic pain development (Clark et al., 2007;Milligan et al., 2004; Verge et al., 2004;Zhuang et al., 2007). CX3CR1-GFP mice of both sexes exhibited similar CX3CR1 expression and microgliosis (Fig. 6 and 7). Thus, only some microglial changes such as upregulations of P2X4 and BDNF and activation of p38 rather than overall morphological changes play a critical role in generating pain hypersensitivity. Caution must be taken when we define the role of microglial "activation" in chronic pain.

\subsection{Sex-dependent p38 signaling in spinal cord microglia}

In males, spinal p38 activation has been studied in a number of inflammatory and neuropathic pain models (Jin et al., 2003;Tsuda et al., 2004;Cui et al., 2006;Kobayashi et al., 2008;Hains and Waxman, 2006;Wen et al., 2009;Li et al., 2010;Katsura et al., 2006). In inflammatory pain p38 activation occurs within tens of minutes of induction and its inhibition causes reduction in phase II pain in the formalin model (Svensson et al., 2005;Berta et al., 2014). In the spinal nerve ligation model of neuropathic pain, p38 activation in microglia occurs around twelve hours postinjury and peaks at three days post-injury (Jin et al., 2003;Zhuang et al., 2005). Intrathecal infusion of the p38 inhibitor SB203580 attenuates neuropathic pain in male rats (Jin et al., 2003b;Tsuda et al., 2004). In males, activation of p38 in microglia results in increased synthesis of the proinflammatory cytokines IL-1 $\beta$, IL-6, and TNF- $\alpha$ (Ji and Suter, 2007). Microglial p38 activation was also implicated in BDNF synthesis and release (Trang et al., 2009; Trang et al., 
2012). These cytokines and neurotrophin are known to cause hyperactivity of dorsal horn neurons resulting in pain hypersensitivity (Coull et al., 2005;Ren and Torres, 2009b;Kawasaki et al., 2008b;Chirila et al., 2014). However, these previous studies were performed in males. In this study, we have shown that CCI predominantly activates spinal p38 in males.

We found that the sex difference is not in microglial activation per se but specifically in p38 signaling. Thus, intrathecal injection of p38 inhibitors skepinone and SB203580 reduced CCI and SNI induced neuropathic pain symptom mechanical allodynia only in male mice (Fig. 2 and Sorge et al., 2015). Intrathecal skepinone and SB203580 also inhibited formalin-induced phase II inflammatory pain in males (Fig. 1)(Berta et al., 2014), although microgliosis is not obvious in this acute inflammatory pain model. Our previous study shows that CCI caused marked increase in sEPSC frequency in lamina IIo neurons of males (Xu et al., 2013b) and we found similar increase in females in this study (Fig. 8). Strikingly, superfusion of skepinone (3 $\mu \mathrm{M})$ in lumbar spinal cord slices suppressed sEPSC frequency in spinal IIo neurons of males but not females after CCI (Fig. 8). It remains to be tested what causes sEPSC increase in female mice.

While activation of p38 may result in the release of pro-inflammatory cytokines such as TNF- $\alpha$ to enhance spinal cord synaptic transmission (Berta et al., 2014), this signaling pathway may be dispensable for microgliosis (Katsura et al., 2006). There are other pathways that may be responsible for microglial proliferation and the structural changes involved in microglial activation. For instance the activation of Src, ERK, Rho/Rock pathways can induce structural changes in microglia including shortening and thickening of processes (Katsura et al., 2006; Calvo et al., 2011; Tatsumi et al., 2015).

\subsection{Central vs. peripheral role of $p 38$ and clinical applications of $p 38$ inhibitors}

This sex difference in the formalin model seems to be localized to the central nervous system. The formalin model of pain produces bi-phasic spontaneous pain behavior. While the first phase is due to a direct effect on peripheral nociceptors (Hunskaar and Hole, 1987), the second phase could be attributed to central sensitization (Hunskaar and Hole, 1987;Dickenson and Sullivan, 1987). Both central and systemic injections of skepinone were capable of sex-specifically 
inhibiting phase II spontaneous pain behavior (Fig. 1), supporting a central role of p38 inhibitor. In contrast, p38 has ongoing peripheral and central contributions to pain behavior in the CCI neuropathic pain model. When the p38 inhibitor skepinone was injected centrally the effect was male-specific. However, when injected systemically or perineurally the peripheral contribution to pain was also profound and mechanical allodynia decreased in both sexes, suggesting that peripheral p38 activation occurs in both sexes while the sex difference is confined to the spinal cord. The peripheral role of p38 in neuropathic pain can be mediated by primary sensory neurons or immune cells in the damaged nerve and makes p38 a good clinical target (Obata and Noguchi, 2004;Ji et al., 2009). Clinical trials have shown p38 inhibitors such as dilmapimod and losmapimod are well tolerated in patients (Anand et al., 2011;Ostenfeld et al., 2013). While an exploratory trial shows significant inhibition of nerve injury-induced neuropathic pain by dilmapimod (Anand et al., 2011), another trial shows that losmapimod could not be differentiated from placebo in neuropathic pain following nerve injury; but the lack of response could reflect inadequate exposure at central sites (Ostenfeld et al., 2013). A novel p38 $\alpha$ MAPK inhibitor, SCIO-469 also shows efficacy in reducing acute postsurgical dental pain (Tong et al., 2012). It will be interesting to reanalyze these clinical data to determine whether there are sex-dependent effects of the p38 inhibitors.

Skepinone has higher selectivity for p38alpha MAPK pathway over JNK and ERK MAPK pathways compared to SB203580 and other p38 MAPK inhibitors as demonstrated in cultured human monocytes (Koeberle et al., 2012). It suppressed LPS-induced TNF release in vivo (Koeberle et al., 2012). It also suppressed LPS-induced TNF release in primary cultures of microglia and shows higher potency that SB203580 (data not shown). Most importantly it has high bioavailability and low-toxicity via oral administration and is highly blood brain barrier permeable (unpublished observations by Stephan Laufer's lab). This makes it a good candidate for human trials as well as for basic science research. Our work shows that local administration via the perineural route, even several days post-injury, is effective in suppressing neuropathic pain for days. Achieving both peripheral and central effects in clinical populations may be possible due to skepinone's high bioavailability, low-toxicity via oral administration, and high CNS permeability, making it an excellent candidate for clinical trial. 


\subsection{Remaining questions and future directions}

While the findings of male-specific microglial signaling in neuropathic pain and inflammatory pain in this study and other studies (Sorge et al., 2015) are remarkable, many questions remain. First, if p38 MAPK activation is involved in the development of persistent pain in males are there separate but similar pathways or cell types involved in females? Recent data suggests that the development of persistent pain in females may be mediated by the recruitment of T-cells into the spinal cord (Sorge et al., 2015). Similarily to activated microglia, T-cells can also release IFN- $\gamma$, BDNF and other proalgesic mediators (Grace et al., 2014). Second, microglia respond to both androgens and estrogens in culture (Brown et al., 2007;Bruce-Keller et al., 2000). In microglia the presence of $17 \beta$-estradiol during LPS stimulation inhibits the release of IL- $1 \beta$ and NO (Bruce-Keller et al., 2000;Loram et al., 2012;Tapia-Gonzalez et al., 2008). However, the mechanisms and the cell-types involved in sex hormone regulation of inflammation are not well understood. Third, microglial signaling has also been shown to contribute to chronic pain in females. In a model of bone cancer pain, p38 MAPK was activated in spinal cord microglia of Wistar female rats in the maintenance phase of cancer pain. Furthermore, intrathecal minocycline and SB203580 effectively reduced late-phase cancer pain (mechanical allodynia and heat hyperalgesia in female rats (Yang et al., 2015). Minocycline was also shown to reduce spinal cord injury induced neuropathic pain in females (Chen et al., 2012). It is possible that microglial activation in females may still be attributable to chronic pain in certain chronic pain conditions. Finally, it remains to be tested whether pro-inflammatory signaling (e.g., TNF and IL-1 $\beta$ ) and anti-inflammatory signaling such as resolvin (Xu et al., 2013a) and GRK2 (Willemen et al., 2010; Kavelaars et al., 2011) in microglia are also sex-dependent.

\section{Acknowledgements}

We thank Dr. Muhammad Yawar Qadri of Duke University for his critical reading of the manuscript. This study was supported by NIH R01 grants DE17794, DE22743, and NS87988 to R.-R.J. S.T. was also supported by a NIH translational training grant from Duke Neurobiology. T.V.V was supported by T32 NIH grant 2T32GM008600 and DoD grant W81XWH-12-2-0129. 


\section{Figure Legends}

Figure 1. Spinal or systemic inhibition of p38 signaling inhibits spontaneous pain behavior in male but not female mice following formalin injection.

(A-C) IT injection of the p-p38 inhibitor skepinone, 30 minutes prior to intraplantar administration of formalin, dose-dependently reduced spontaneous Phase II pain behavior in male but not female mice. (A,B) Time course of formalin-induced spontaneous pain in males (A) and females (B). (C) Formalin-induced Phase I (0-10 min) and Phase II (15-45 min) responses. $* P<0.05, * * P<0.01$, in comparison to same sex saline control, One-Way ANOVA, $\mathrm{n}=6-8$ mice per sex per group. n.s., not significant. (D,E) IP administration of skepinone 1 hour prior to formalin injection reduced spontaneous Phase II pain behavior in male but not female mice. (D) Time course of formalin-induced spontaneous pain in males and females. (E) Formalin-induced Phase I (0-10 $\mathrm{min})$ and Phase II (15-45 min) responses. $* P<0.05, * * P<0.01$, in comparison to same sex saline control. ${ }^{\#} P<0.05$, compared to opposite sex. One-Way ANOVA, n = 6-8 mice per sex per group.

Figure 2. Spinal inhibition of p38 inhibits CCI-induced mechanical allodynia in male mice and rats but not in female mice and rats one week after nerve injury.

(A) IT injection of $30 \mu \mathrm{g}$ per mouse of the p-p38 inhibitor skepinone 7 days post-CCI significantly increased paw withdrawal threshold in males but not female mice. $* * P<0.01$, in comparison to same sex vehicle (saline). ${ }^{\#} P<0.05$ in comparison to opposite sex drug, Two-Way ANOVA, repeated measures, $n=6$ mice per sex per group. (B) IT injection of $30 \mu \mathrm{g}$ per mouse of the p-p38 inhibitor skepinone 21 days post-CCI had no effects on mechanical allodynia in both male and female mice. $P>0.05$, Two-Way ANOVA, repeated measures, $\mathrm{n}=5$ mice per sex per group. (C) IT injection of $60 \mu \mathrm{g}$ per rat of the p-p38 inhibitor skepinone 7 days post-CCI significantly increased paw withdrawal threshold in male but not female rats. $* P<0.05$, in comparison to same sex. ${ }^{\#} P<0.05$ in comparison to opposite sex, Two-Way ANOVA, repeated measures, $n=6$ rats per sex per group.

Figure 3. Systemic or peri-neural (peri-sciatic) inhibition of p38 signaling decreases allodynia in both sexes. 
(A) IP administration of $30 \mathrm{mg} / \mathrm{kg}$ skepinone 7 days post-CCI reduced mechanical allodynia in both male and female mice. $* P<0.05, * * P<0.01$, $* * * P<0.001$, in comparison to same sex preinjection control. Two-Way ANOVA, repeated measures, $\mathrm{n}=6$ mice per sex per group. n.s., not significant. (B) Peri-sciatic (peri-neural) administration of $18 \mu \mathrm{g}$ per mouse skepinone 7 days post-CCI reduced mechanical allodynia in both sexes. $* P<0.05$, $* * P<0.01$, $* * * P<0.001$, in comparison to same sex saline control. Two-Way ANOVA, repeated measures, $\mathrm{n}=6$ mice per sex per group. n.s., not significant.

Figure 4. Spinal dorsal horn microglia display morphological activation, increased IBA-1 staining intensity, and proliferation in response to $\mathrm{CCI}$ in both sexes.

(A,B) Immunofluorescent staining with the microglial marker IBA-1 (red) in lumbar dorsal horn sections showing both contralateral (Contra) and ipsilateral (Ipsi) sides of male (A) and female (B) mice 7 days post-CCI. Scales, 50 and $100 \mu \mathrm{m}$. (C) Quantification IBA-1 immunofluorescence from mouse lumbar sections shows a significant increase in fluorescent intensity and the number of IBA-1 positive cells in the ipsilateral dorsal horn in both male and female mice. $* P<0.05$, $* * * P<0.001$, comparing ipsilateral and contralateral dorsal horn of same sex. Two-tailed Student $\mathrm{t}$-test, $\mathrm{n}=3$ mice per sex per group, 3 sections per mouse.

Figure 5. Nerve injury induces p38 phosphorylation in spinal cord dorsal horn of male but not female mice.

(A,B) Western blots of p-p38 and p38 from male (A) and female (B) contralateral (Contra) and ipsilateral (Ipsi) lumbar dorsal horn samples (L4-6) obtained 7 days post-CCI. GAPDH was used as a loading control. (C,D) Quantification of the intensity of p-p38 (C) and p38 (D) western bands shows that p-p38 and p38 levels are significantly increased in male but not female ipsilateral dorsal horn compared to contralateral $\left({ }^{*} P<0.05\right)$ or female ipsilateral dorsal horn $\left({ }^{\#} P\right.$ $<0.05$ ). Values were normalized to GAPDH as a loading control then to the contralateral dorsal horn. Two-tailed Student t-test, $\mathrm{n}=4$ mice per sex per group. (E) Quantification of the ratio of $\mathrm{p}$ p38/p38 western bands in ipsilateral and contralateral dorsal horn of males and females. $* P<$ 0.05 , compared to contralateral side, $\mathrm{n}=4$ mice per sex per group. n.s., not significant. 
Figure 6. Nerve injury induces spinal CX3CR1 expression in both sexes and spinal microglial p38 activation primarily in male mice 7 days post CCI.

(A, B) CX3CR1-GFP (green) and immunofluorescent staining of p-p38 (red) in dorsal horn sections from CX3CR1-GFP mice of a male (A) and a female (B) 7 days post-CCI. GFP shows morphological activation and proliferation of microglia in the dorsal horn of both male and female mice. Note that p-p38 staining is colocalized with the microglial marker CX3CR1. Also note that p-p38 staining is stronger in male microglia. Scales, $50 \mu \mathrm{m}$ (up panel in B) and $25 \mu \mathrm{m}$ (low panel in B).

Figure 7. Nerve injury induces spinal microglial proliferation in both sexes and spinal microglial p38 activation primarily in male mice 7 days post CCI.

(A) Quantification from lumbar spinal cord sections of CX3CR1-GFP mice shows a significant increase in the number of GFP positive microglia in the medial superficial dorsal horn ipsilateral to $\mathrm{CCI}$ in both male and female mice. $* * * P<0.001$ comparing ipsilateral and contralateral of same sex, two-tailed Student t-test, $\mathrm{n}=3$ mice per sex per group. n.s., not significant. (B) Quantification of p-p38 positive cells in the medial superficial dorsal horn from lumbar spinal cord sections shows a significant increase in the number of p-p38 positive cells in in both male and female mice. ${ }^{*} P<0.05$, comparison between ipsilateral and contralateral of same sex, $\mathrm{n}=4$ mice per sex per group. n.s., not significant. (C) Quantification of p-p38 immunofluorescence in the medial superficial dorsal horn from lumbar spinal cord sections shows a significant increase in intensity of p-p38 immunofluorescence in both male and female mice and further increase in male mice. ${ }^{*} P<0.05$, comparison between ipsilateral and contralateral of same sex; ${ }^{*} P<0.05$, male vs. female, two-tailed Student t-test, $n=4$ mice per sex per group. Four-five spinal cord sections were included per mouse for quantification.

Figure 8. Skepinone inhibits the frequency of spontaneous excitatory postsynaptic currents (sEPSCs) in lamina IIo neurons of spinal cord slices in male but not female mice 7 days post CCI. (A) Traces of sEPSCs in lamina IIo neurons with and without skepinone $(3 \mu \mathrm{M})$ treatment. (B) Frequency and amplitude of sEPSCs, $* P<0.01$, two-tailed Student t-test, $\mathrm{n}=5$ neurons/group. 


\section{References}

Anand P, Shenoy R, Palmer JE, Baines AJ, Lai RY, Robertson J, Bird N, Ostenfeld T, Chizh BA (2011) Clinical trial of the p38 MAP kinase inhibitor dilmapimod in neuropathic pain following nerve injury. Eur J Pain 15:1040-1048.

Beggs S, Salter MW (2007) Stereological and somatotopic analysis of the spinal microglial response to peripheral nerve injury. Brain Behav Immun 21:624-633.

Bennett GJ, Xie YK (1988) A peripheral mononeuropathy in rat that produces disorders of pain sensation like those seen in man. Pain 33:87-107.

Berta T, Park CK, Xu ZZ, Xie RG, Liu T, Lu N, Liu YC, Ji RR (2014) Extracellular caspase-6 drives murine inflammatory pain via microglial TNF-alpha secretion. J Clin Invest 124:1173-1186.

Brown CM, Xu Q, Okhubo N, Vitek MP, Colton CA (2007) Androgen-mediated immune function is altered by the apolipoprotein E gene. Endocrinology 2007/03/31:3383-3390.

Bruce-Keller AJ, Keeling JL, Keller JN, Huang FF, Camondola S, Mattson MP (2000) Antiinflammatory effects of estrogen on microglial activation. Endocrinology 2000/10/03:3646-3656.

Calvo M, Bennett DL (2012) The mechanisms of microgliosis and pain following peripheral nerve injury. Exp Neurol 234:271-282.

Calvo M, Zhu N, Grist J, Ma Z, Loeb JA, Bennett DL (2011) Following nerve injury neuregulin-1 drives microglial proliferation and neuropathic pain via the MEK/ERK pathway. Glia 59:554-568.

Chen G, Park CK, Xie RG, Berta T, Nedergaard M, Ji RR (2014) Connexin-43 induces chemokine release from spinal cord astrocytes to maintain late-phase neuropathic pain in mice. Brain 137:2193-2209.

Chen MJ, Kress B, Han X, Moll K, Peng W, Ji RR, Nedergaard M (2012) Astrocytic CX43 hemichannels and gap junctions play a crucial role in development of chronic neuropathic pain following spinal cord injury. Glia 60:1660-1670.

Chirila AM, Brown TE, Bishop RA, Bellono NW, Pucci FG, Kauer JA (2014) Long-term potentiation of glycinergic synapses triggered by interleukin 1beta. Proc Natl Acad Sci U S A 111:8263-8268.

Cho IH, Chung YM, Park CK, Park SH, Lee H, Kim D, Piao ZG, Choi SY, Lee SJ, Park K, Kim JS, Jung SJ, Oh SB (2006) Systemic administration of minocycline inhibits formalin-induced inflammatory pain in rat. Brain research 2006/01/24:208-214.

Clark AK, D'Aquisto F, Gentry C, Marchand F, McMahon SB, Malcangio M (2006) Rapid co-release of interleukin 1 beta and caspase 1 in spinal cord inflammation. J Neurochem 99:868-880. 
Clark AK, Yip PK, Grist J, Gentry C, Staniland AA, Marchand F, Dehvari M, Wotherspoon G, Winter J, Ullah J, Bevan S, Malcangio M (2007) Inhibition of spinal microglial cathepsin S for the reversal of neuropathic pain. Proc Natl Acad Sci U S A 104:10655-10660.

Colburn RW, DeLeo JA, Rickman AJ, Yeager MP, Kwon P, Hickey WF (1997) Dissociation of microglial activation and neuropathic pain behaviors following peripheral nerve injury in the rat. J Neuroimmunol 79:163-175.

Coull JA, Beggs S, Boudreau D, Boivin D, Tsuda M, Inoue K, Gravel C, Salter MW, De Koninck Y (2005) BDNF from microglia causes the shift in neuronal anion gradient underlying neuropathic pain. Nature 438:1017-1021.

Cui Y, Chen Y, Zhi JL, Guo RX, Feng JQ, Chen PX (2006) Activation of p38 mitogen-activated protein kinase in spinal microglia mediates morphine antinociceptive tolerance. Brain Res 1069:235-243.

Dickenson AH, Sullivan AF (1987) Subcutaneous formalin-induced activity of dorsal horn neurones in the rat: differential response to an intrathecal opiate administered pre or post formalin. Pain 30:349-360.

Dixon WJ (1980) Efficient analysis of experimental observations. Annu Rev Pharmacol Toxicol 20:441462.

Echeverry S, Shi XQ, Zhang J (2008) Characterization of cell proliferation in rat spinal cord following peripheral nerve injury and the relationship with neuropathic pain. Pain 135:37-47.

Grace PM, Hutchinson MR, Maier SF, Watkins LR (2014) Pathological pain and the neuroimmune interface. Nature reviews Immunology 14:217-231.

Hains BC, Waxman SG (2006) Activated microglia contribute to the maintenance of chronic pain after spinal cord injury. The Journal of neuroscience : the official journal of the Society for Neuroscience 2006/04/21:4308-4317.

Hua XY, Svensson Cl, Matsui T, Fitzsimmons B, Yaksh TL, Webb M (2005) Intrathecal minocycline attenuates peripheral inflammation-induced hyperalgesia by inhibiting p38 MAPK in spinal microglia. Eur J Neurosci 22:2431-2440.

Hunskaar S, Hole K (1987) The formalin test in mice: dissociation between inflammatory and noninflammatory pain. Pain 30:103-114.

Hylden JL, Wilcox GL (1980) Intrathecal morphine in mice: a new technique. Eur J Pharmacol 67:313-316.

Inoue K, Tsuda M (2009) Microglia and neuropathic pain. Glia 57:1469-1479.

Ji RR, Baba H, Brenner GJ, Woolf CJ (1999) Nociceptive-specific activation of ERK in spinal neurons contributes to pain hypersensitivity. Nat Neurosci 2:1114-1119.

Ji RR, Berta T, Nedergaard M (2013) Glia and pain: Is chronic pain a gliopathy? Pain 154 Suppl 1:S10-28. 
Ji RR, Gereau RW, Malcangio M, Strichartz GR (2009) MAP kinase and pain. Brain research reviews 20:135-148.

Ji RR, Suter MR (2007) p38 MAPK, microglial signaling, and neuropathic pain. Mol Pain 3:33.

Jin SX, Zhuang ZY, Woolf CJ, Ji RR (2003) p38 mitogen-activated protein kinase is activated after a spinal nerve ligation in spinal cord microglia and dorsal root ganglion neurons and contributes to the generation of neuropathic pain. J Neurosci 23:4017-4022.

Katsura H, Obata K, Mizushima T, Sakurai J, Kobayashi K, Yamanaka H, Dai Y, Fukuoka T, Sakagami M, Noguchi K (2006) Activation of Src-family kinases in spinal microglia contributes to mechanical hypersensitivity after nerve injury. J Neurosci 26:8680-8690.

Kavelaars A, Eijkelkamp N, Willemen HL, Wang H, Carbajal AG, Heijnen CJ (2011) Microglial GRK2: a novel regulator of transition from acute to chronic pain. Brain Behav Immun 25:1055-1060.

Kawasaki Y, Zhang L, Cheng JK, Ji RR (2008) Cytokine mechanisms of central sensitization: distinct and overlapping role of interleukin-1beta, interleukin-6, and tumor necrosis factor-alpha in regulating synaptic and neuronal activity in the superficial spinal cord. J Neurosci 28:5189-5194.

Kobayashi K, Yamanaka H, Fukuoka T, Dai Y, Obata K, Noguchi K (2008) P2Y12 receptor upregulation in activated microglia is a gateway of p38 signaling and neuropathic pain. J Neurosci 28:2892-2902.

Koeberle SC, Romir J, Fischer S, Koeberle A, Schattel V, Albrecht W, Grutter C, Werz O, Rauh D, Stehle T, Laufer SA (2012) Skepinone-L is a selective p38 mitogen-activated protein kinase inhibitor. Nature chemical biology 8:141-143.

Ledeboer A, Sloane EM, Milligan ED, Frank MG, Mahony JH, Maier SF, Watkins LR (2005) Minocycline attenuates mechanical allodynia and proinflammatory cytokine expression in rat models of pain facilitation. Pain 20:71-83.

Li K, Lin T, Cao Y, Light AR, Fu KY (2010) Peripheral formalin injury induces 2 stages of microglial activation in the spinal cord. The journal of pain 22:1056-1065.

Loram LC, Sholar PW, Taylor FR, Wiesler JL, Babb JA, Strand KA, Berkelhammer D, Day HE, Maier SF, Watkins LR (2012) Sex and estradiol influence glial pro-inflammatory responses to lipopolysaccharide in rats. Psychoneuroendocrinology 14:1688-1699.

McMahon SB, Malcangio M (2009) Current challenges in glia-pain biology. Neuron 64:46-54.

Milligan ED, Watkins LR (2009) Pathological and protective roles of glia in chronic pain. Nat Rev Neurosci 10:23-36.

Milligan ED, Zapata V, Chacur M, Schoeniger D, Biedenkapp J, O'Connor KA, Verge GM, Chapman G, Green P, Foster AC, Naeve GS, Maier SF, Watkins LR (2004) Evidence that exogenous and endogenous fractalkine can induce spinal nociceptive facilitation in rats. Eur J Neurosci 20:2294-2302. 
Mogil JS (2012) Sex differences in pain and pain inhibition: multiple explanations of a controversial phenomenon. Nature reviews Neuroscience 21:859-866.

Mogil JS, Chanda ML (2005) The case for the inclusion of female subjects in basic science studies of pain. Pain 16:1-5.

Obata K, Noguchi K (2004) MAPK activation in nociceptive neurons and pain hypersensitivity. Life Sci 74:2643-2653.

Ostenfeld T, Krishen A, Lai RY, Bullman J, Baines AJ, Green J, Anand P, Kelly M (2013) Analgesic efficacy and safety of the novel p38 MAP kinase inhibitor, losmapimod, in patients with neuropathic pain following peripheral nerve injury: a double-blind, placebo-controlled study. Eur J Pain 17:844-857.

Park CK, Lu N, Xu ZZ, Liu T, Serhan CN, Ji RR (2011) Resolving TRPV1- and TNF-a-mediated spinal cord synaptic plasticity and inflammatory pain with neuroprotectin D1. J Neurosci 31:15072-15085.

Pleis JR, Ward BW, Lucas JW (2010) Summary health statistics for U.S. adults: National Health Interview Survey, 2009. Vital and health statistics Series 10, Data from the National Health Survey 13:1-207.

Ren K, Dubner R (2010) Interactions between the immune and nervous systems in pain. Nat Med 16:1267-1276.

Ren K, Torres R (2009) Role of interleukin-1beta during pain and inflammation. Brain Res Rev 60:57-64.

Sorge RE, Lacroix-Fralish ML, Tuttle AH, Sotocinal SG, Austin JS, Ritchie J, Chanda ML, Graham AC, Topham L, Beggs S, Salter MW, Mogil JS (2011) Spinal cord Toll-like receptor 4 mediates inflammatory and neuropathic hypersensitivity in male but not female mice. J Neurosci 31:15450-15454.

Sorge RE, et al. (2015) Different immune cells mediate mechanical pain hypersensitivity in male and female mice. Nat Neurosci. 18:1081-3.

Suter MR, Wen YR, Decosterd I, Ji RR (2007) Do glial cells control pain? Neuron Glia Biol 3:255-268.

Svensson Cl, Fitzsimmons B, Azizi S, Powell HC, Hua XY, Yaksh TL (2005) Spinal p38beta isoform mediates tissue injury-induced hyperalgesia and spinal sensitization. J Neurochem 92:1508-1520.

Svensson $\mathrm{Cl}$, Hua XY, Protter AA, Powell HC, Yaksh TL (2003) Spinal p38 MAP kinase is necessary for NMDA-induced spinal PGE(2) release and thermal hyperalgesia. Neuroreport 14:1153-1157.

Tapia-Gonzalez S, Carrero P, Pernia O, Garcia-Segura LM, Diz-Chaves Y (2008) Selective oestrogen receptor (ER) modulators reduce microglia reactivity in vivo after peripheral inflammation: potential role of microglial ERs. The Journal of endocrinology 8:219-230.

Tatsumi E, Yamanaka H, Kobayashi K, Yagi H, Sakagami M, Noguchi K (2015) RhoA/ROCK pathway mediates p38 MAPK activation and morphological changes downstream of $\mathrm{P} 2 \mathrm{Y} 12 / 13$ receptors in spinal microglia in neuropathic pain. Glia 63:216-228. 
Taves S, Berta T, Chen G, Ji RR (2013) Microglia and spinal cord synaptic plasticity in persistent pain. Neural Plast 2013:753656.

Tong SE, Daniels SE, Black P, Chang S, Protter A, Desjardins PJ (2012) Novel p38alpha mitogen-activated protein kinase inhibitor shows analgesic efficacy in acute postsurgical dental pain. J Clin Pharmacol 52:717-728.

Trang T, Beggs S, Salter MW (2012) ATP receptors gate microglia signaling in neuropathic pain. Exp Neurol 234:354-361.

Trang T, Beggs S, Wan X, Salter MW (2009) P2X4-receptor-mediated synthesis and release of brainderived neurotrophic factor in microglia is dependent on calcium and p38-mitogen-activated protein kinase activation. J Neurosci 29:3518-3528.

Tsuda M, Inoue K, Salter MW (2005) Neuropathic pain and spinal microglia: a big problem from molecules in "small" glia. Trends Neurosci 28:101-107.

Tsuda M, Mizokoshi A, Shigemoto-Mogami Y, Koizumi S, Inoue K (2004) Activation of p38 mitogenactivated protein kinase in spinal hyperactive microglia contributes to pain hypersensitivity following peripheral nerve injury. Glia 45:89-95.

Tsuda M, Shigemoto-Mogami Y, Koizumi S, Mizokoshi A, Kohsaka S, Salter MW, Inoue K (2003) P2X4 receptors induced in spinal microglia gate tactile allodynia after nerve injury. Nature 424:778-783.

Verge GM, Milligan ED, Maier SF, Watkins LR, Naeve GS, Foster AC (2004) Fractalkine (CX3CL1) and fractalkine receptor (CX3CR1) distribution in spinal cord and dorsal root ganglia under basal and neuropathic pain conditions. Eur J Neurosci 20:1150-1160.

Wen YR, Suter MR, Ji RR, Yeh GC, Wu YS, Wang KC, Kohno T, Sun WZ, Wang CC (2009) Activation of p38 mitogen-activated protein kinase in spinal microglia contributes to incision-induced mechanical allodynia. Anesthesiology 110:155-165.

Willemen HL, Eijkelkamp N, Wang H, Dantzer R, Dorn GW, Kelley KW, Heijnen CJ, Kavelaars A (2010) Microglial/macrophage GRK2 determines duration of peripheral IL-1beta-induced hyperalgesia: contribution of spinal cord CX3CR1, p38 and IL-1 signaling. Pain 150:550-560.

Xu ZZ, Berta T, Ji RR (2013a) Resolvin e1 inhibits neuropathic pain and spinal cord microglial activation following peripheral nerve injury. Journal of neuroimmune pharmacology 11:37-41.

Xu ZZ, Liu XJ, Berta T, Park CK, Lu N, Serhan CN, Ji RR (2013b) Neuroprotectin/Protectin D1 protects neuropathic pain in mice after nerve trauma. Ann Neurol 74: 490-495.

Yan X, Weng HR (2013) Endogenous interleukin-1beta in neuropathic rats enhances glutamate release from the primary afferents in the spinal dorsal horn through coupling with presynaptic NMDA receptors. J Biol Chem 288:30544-57. 
Yang Y, Li H, Li TT, Luo H, Gu XY, Lu N, Ji RR, Zhang YQ (2015) Delayed Activation of Spinal Microglia Contributes to the Maintenance of Bone Cancer Pain in Female Wistar Rats via P2X7 Receptor and IL-18. J Neurosci 35:7950-7963.

Zhang H, Nei H, Dougherty PM (2010) A p38 mitogen-activated protein kinase-dependent mechanism of disinhibition in spinal synaptic transmission induced by tumor necrosis factor-alpha. J Neurosci 30:12844-12855.

Zhang H, Yoon SY, Zhang H, Dougherty PM (2012) Evidence that spinal astrocytes but not microglia contribute to the pathogenesis of Paclitaxel-induced painful neuropathy. J Pain 13:293-303.

Zhang J, Shi XQ, Echeverry S, Mogil JS, De Koninck Y, Rivest S (2007) Expression of CCR2 in both resident and bone marrow-derived microglia plays a critical role in neuropathic pain. J Neurosci 27:12396-12406.

Zhuang ZY, Gerner P, Woolf CJ, Ji RR (2005) ERK is sequentially activated in neurons, microglia, and astrocytes by spinal nerve ligation and contributes to mechanical allodynia in this neuropathic pain model. Pain 114:149-159.

Zhuang ZY, Kawasaki Y, Tan PH, Wen YR, Huang J, Ji RR (2007) Role of the CX3CR1/p38 MAPK pathway in spinal microglia for the development of neuropathic pain following nerve injury-induced cleavage of fractalkine. Brain Behav Immun 21:642-651. 
A

IT injection of skepinone in male

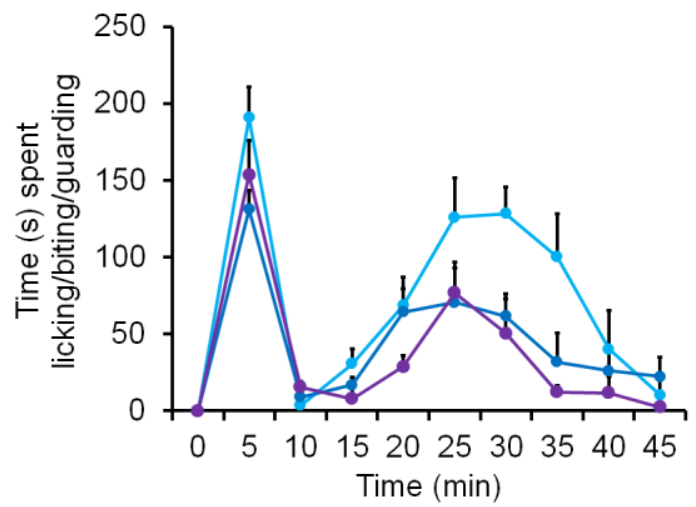

C

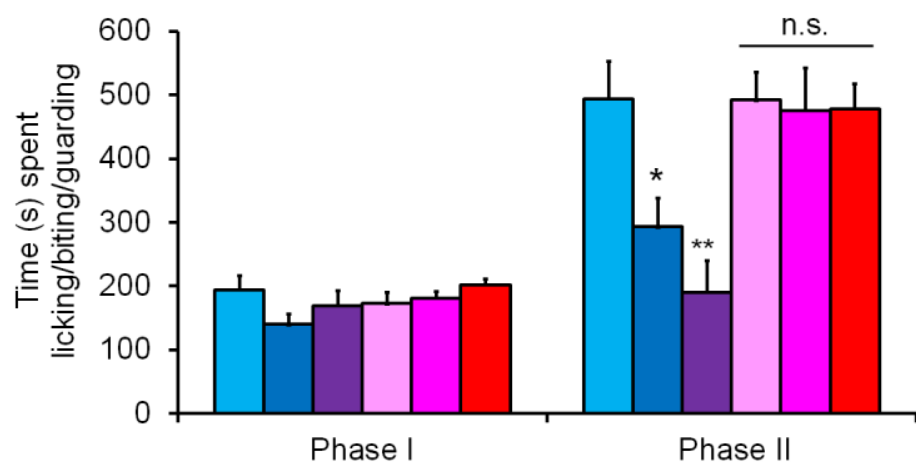

D

IP injection of skepinone

$\square$ Male, saline

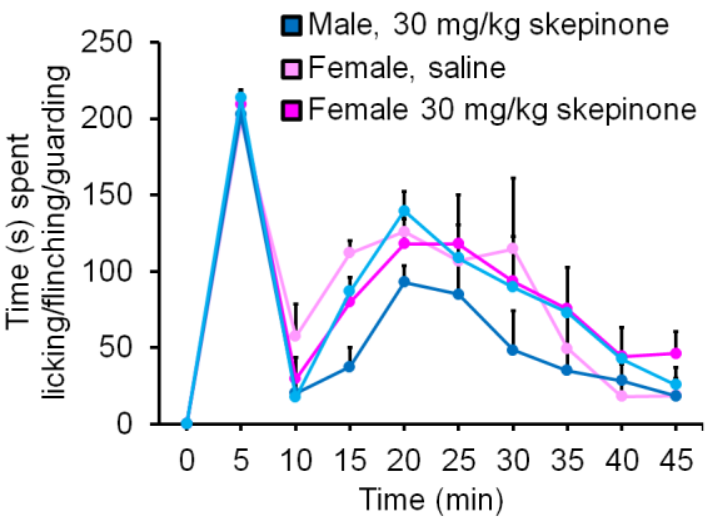

B

IT injection of skepinone in female

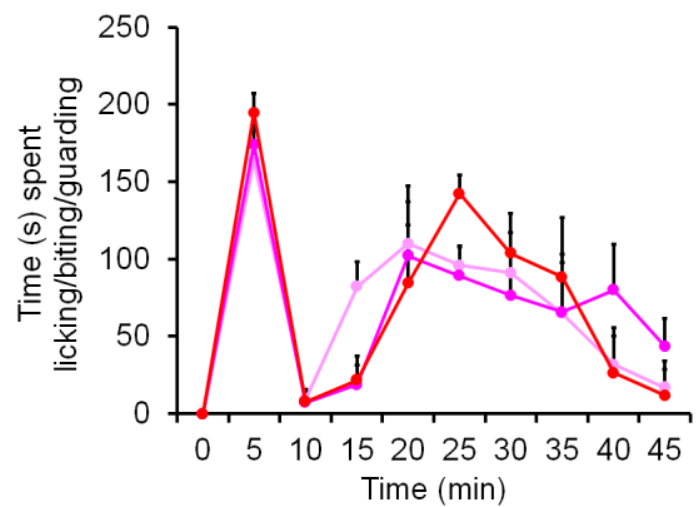

E

IP injection of skepinone

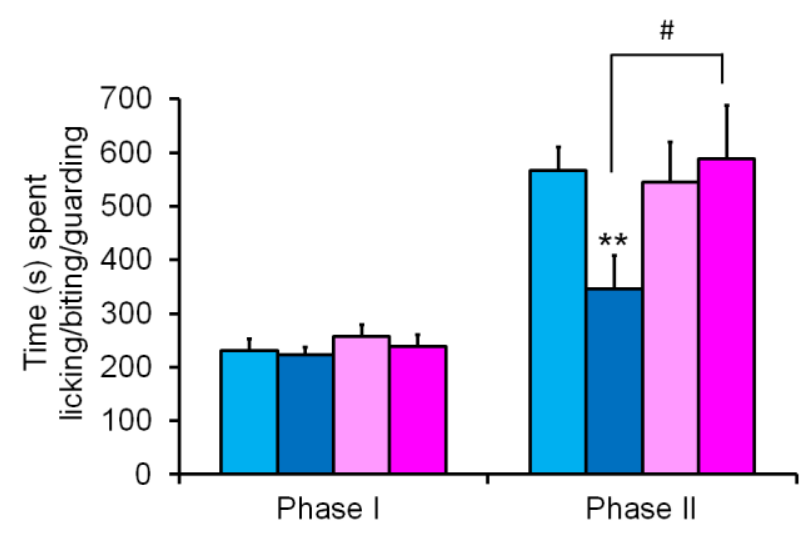




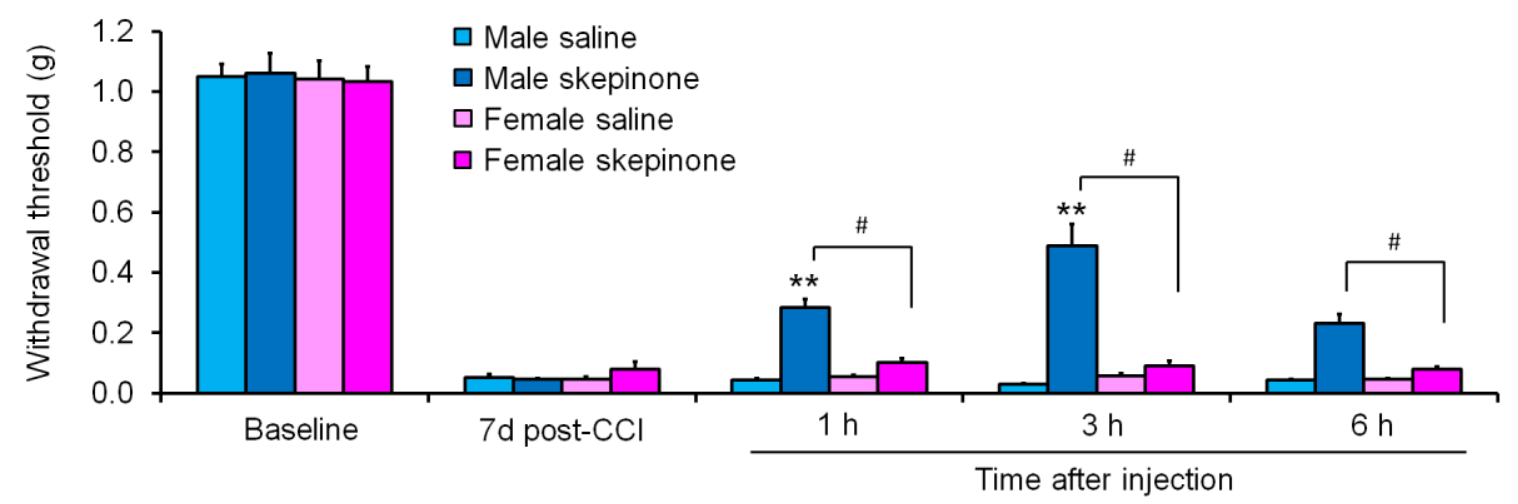

B

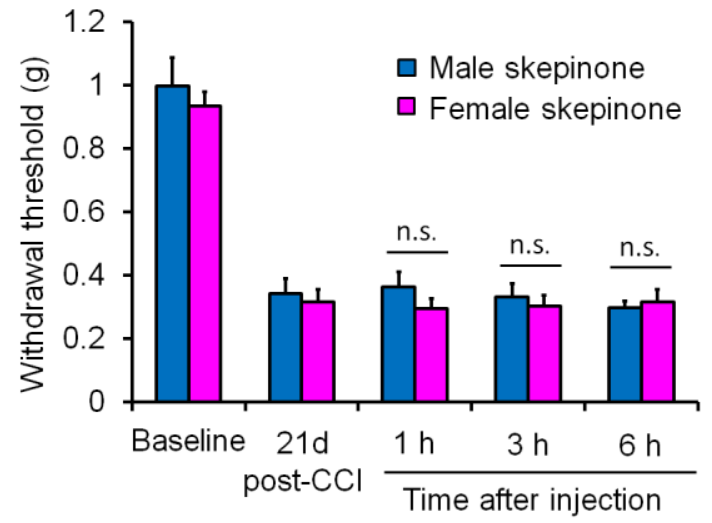

C

IT injection of skepinone $7 \mathrm{~d}$ after $\mathrm{CCl}$, rats

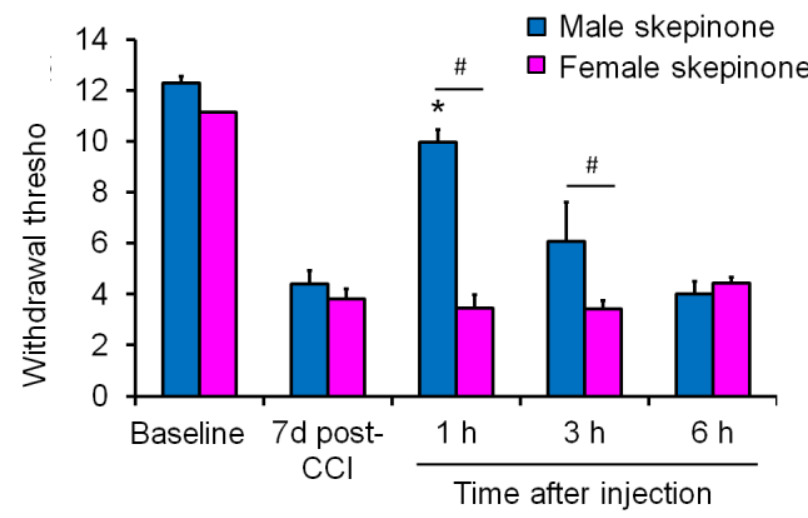


A

IP injection of skepinone

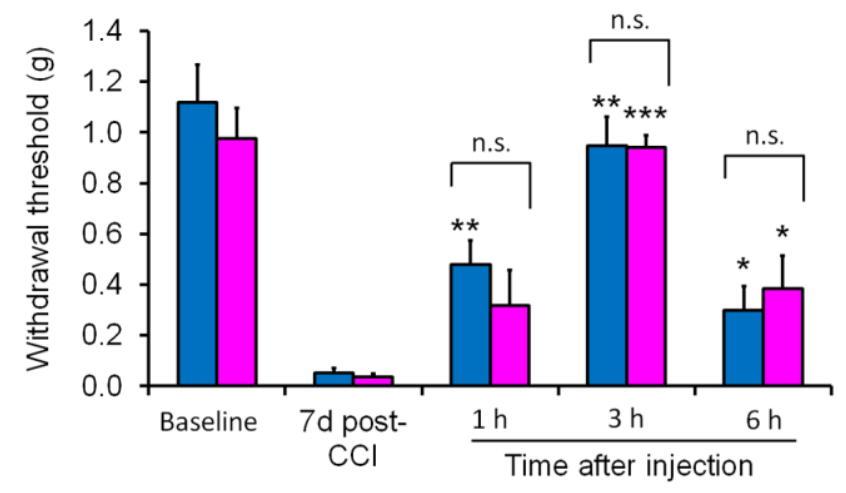

B Peri-neural injection of skepinone

口 Male skepinone $30 \mathrm{mg} / \mathrm{kg}$

Female skepinone $30 \mathrm{mg} / \mathrm{kg}$

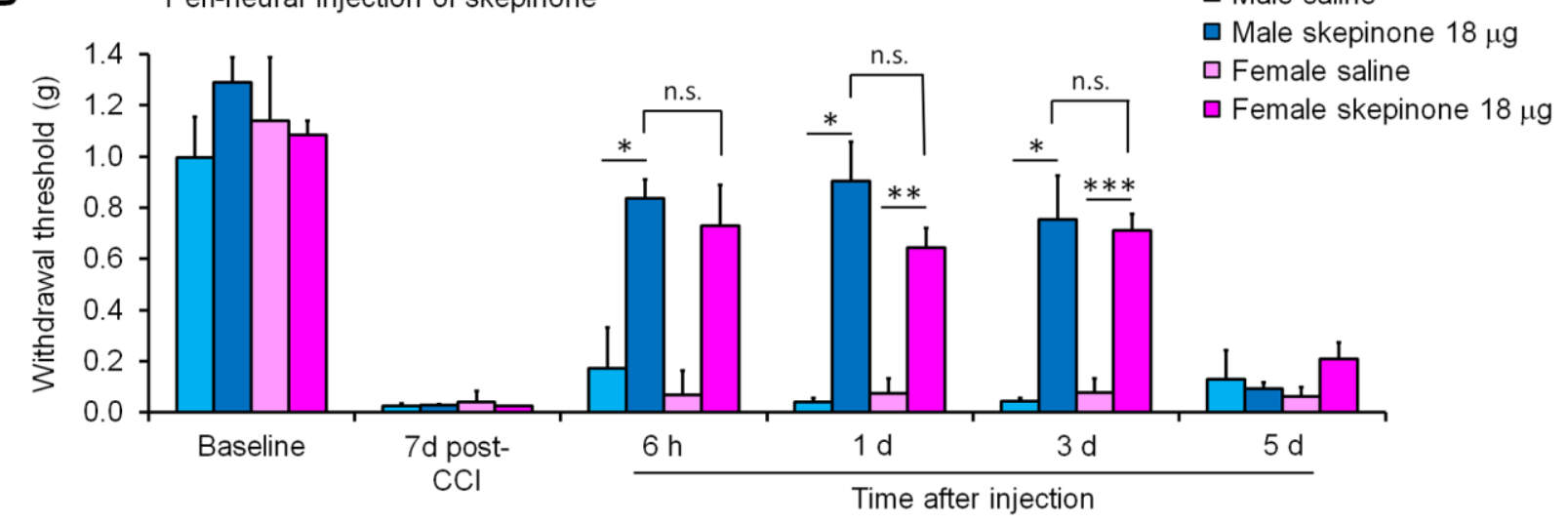


A Male- $\mathrm{CCl} 7 \mathrm{~d}$
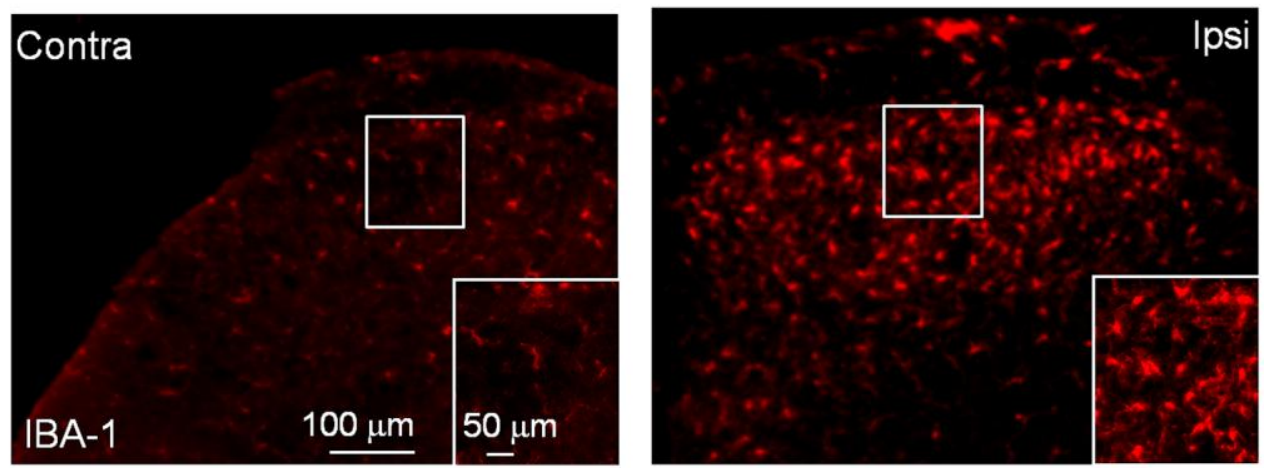

B Female - $\mathrm{CCl} 7 \mathrm{~d}$
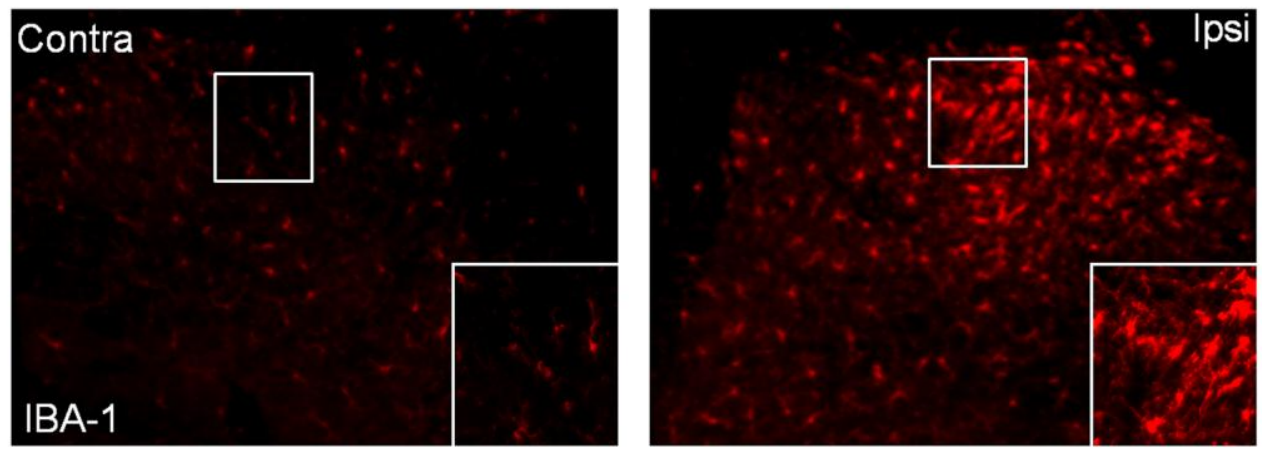

C

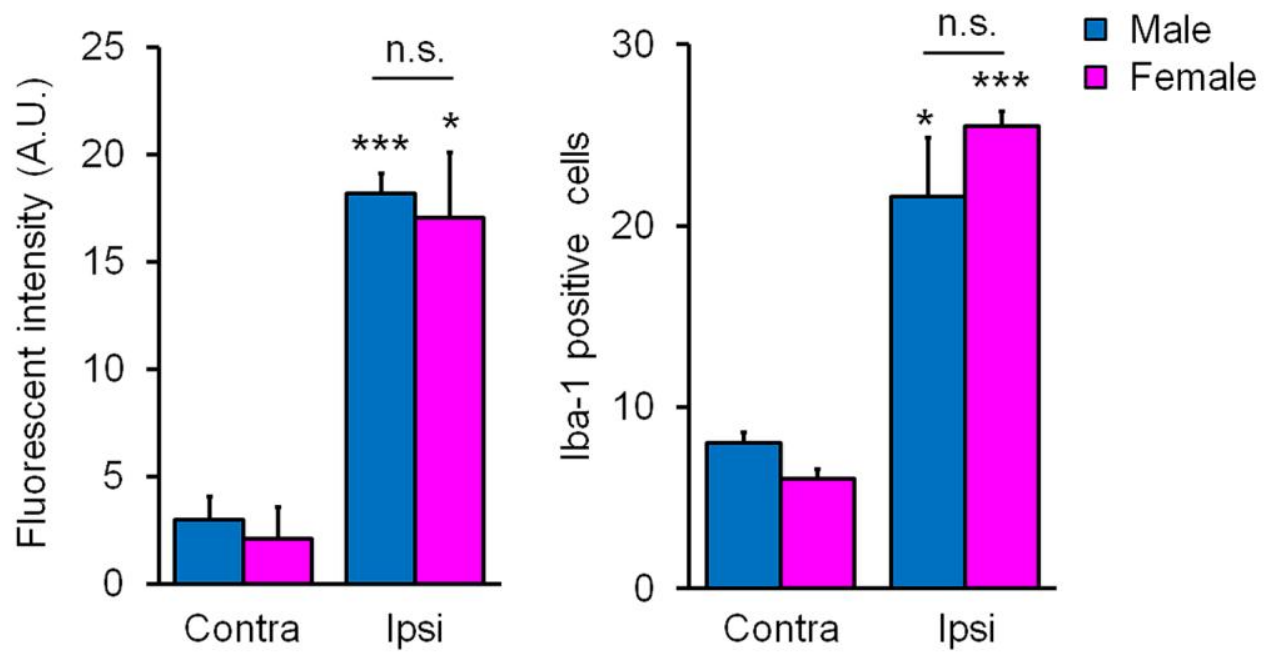



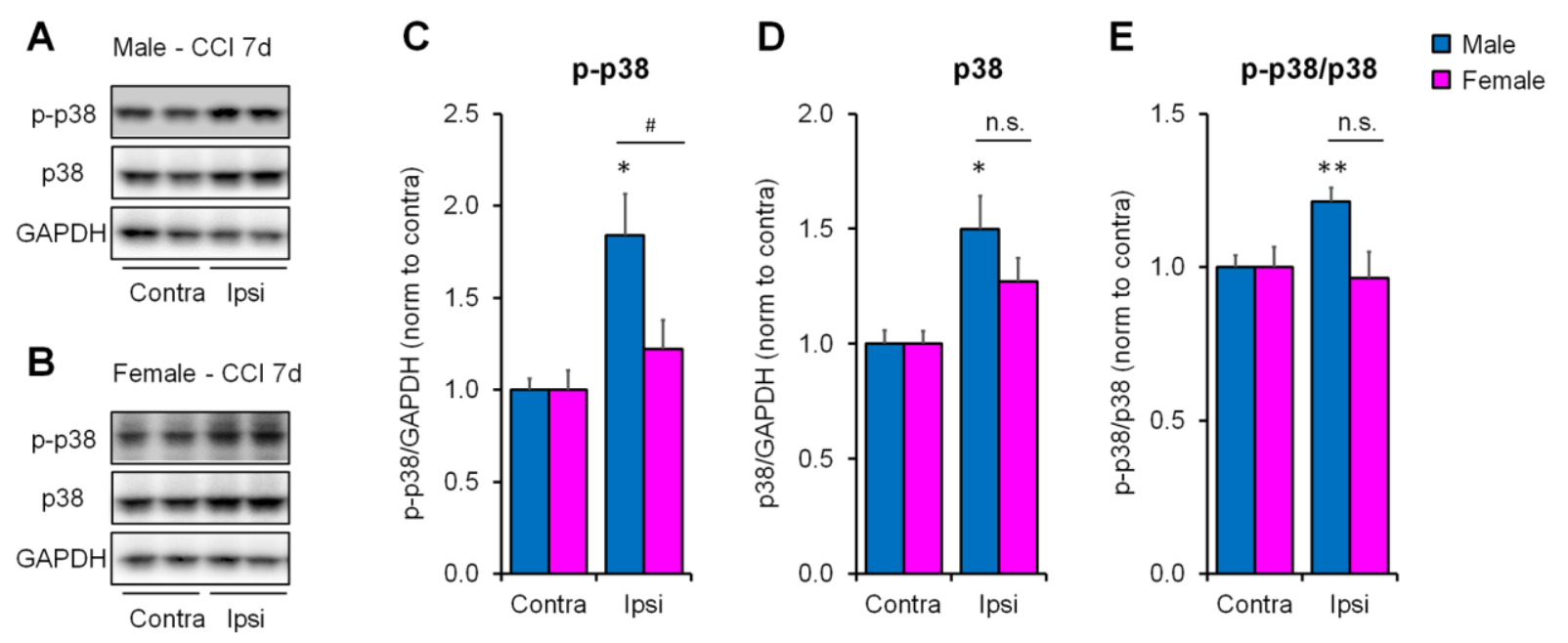
A Male- $\mathrm{CCl} 7 \mathrm{~d}$
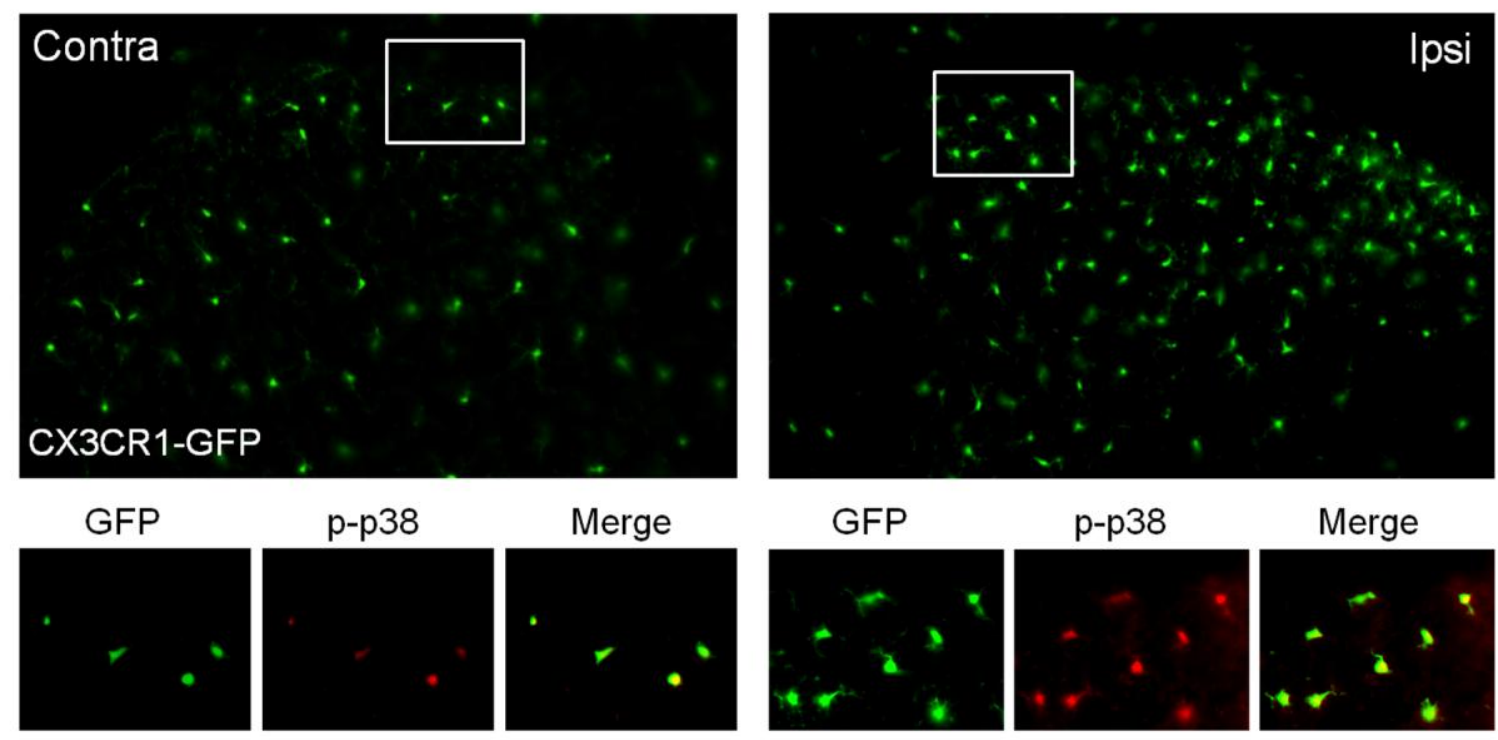

Merge

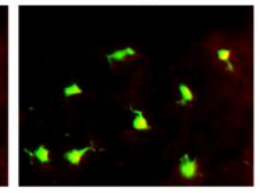

B Female - $\mathrm{CCl} 7 \mathrm{~d}$
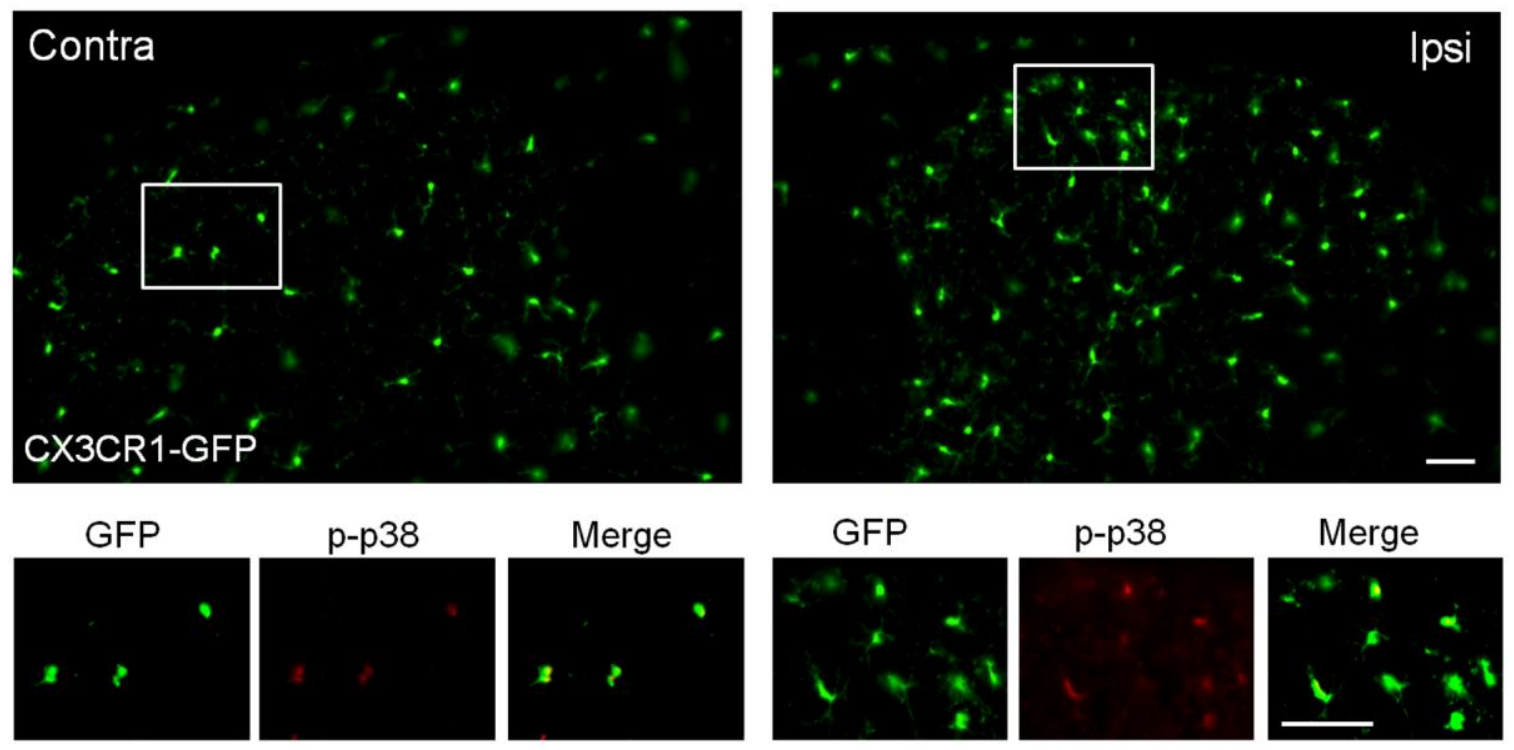
A

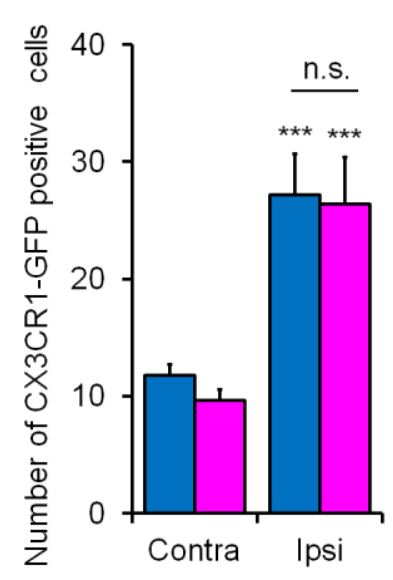

B

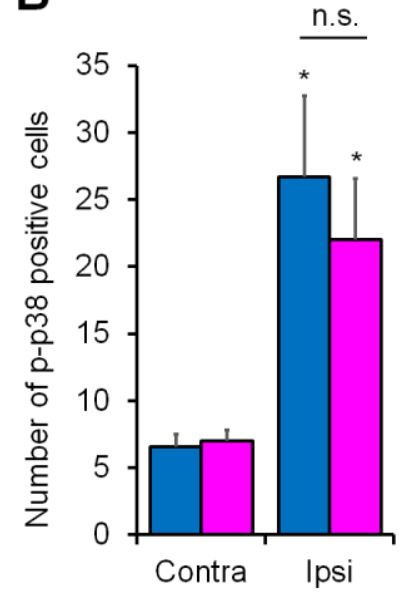

C

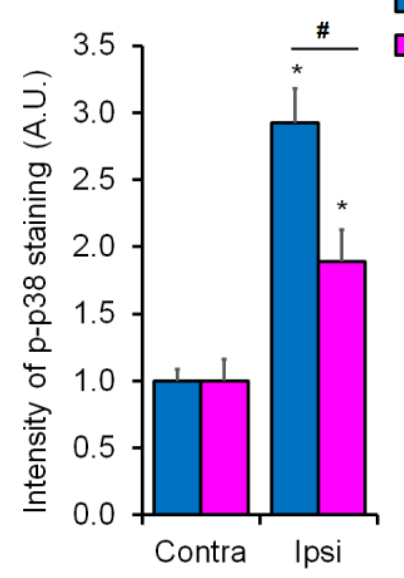




\section{A}

$\mathrm{CCl} 7 \mathrm{~d}$, no treatment
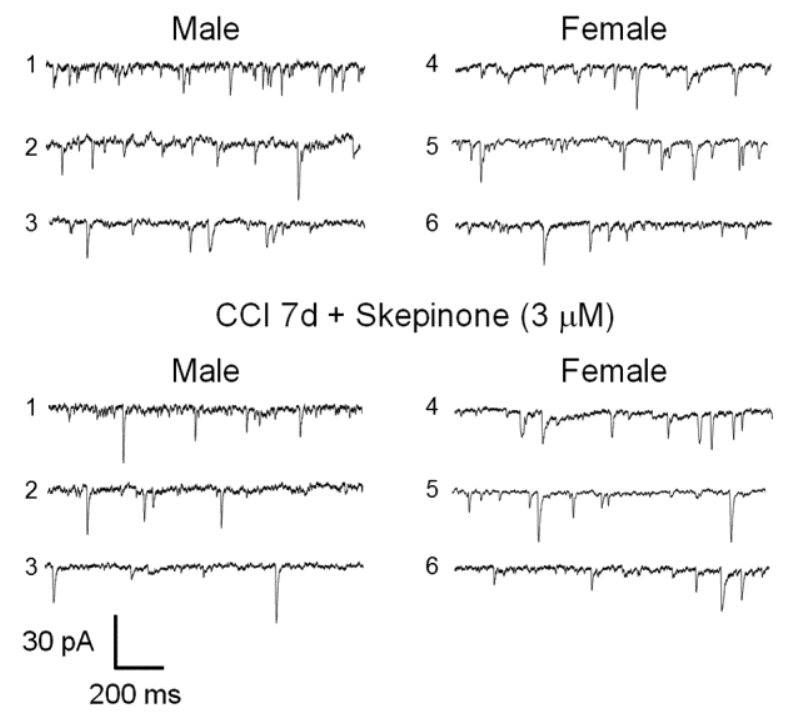

B
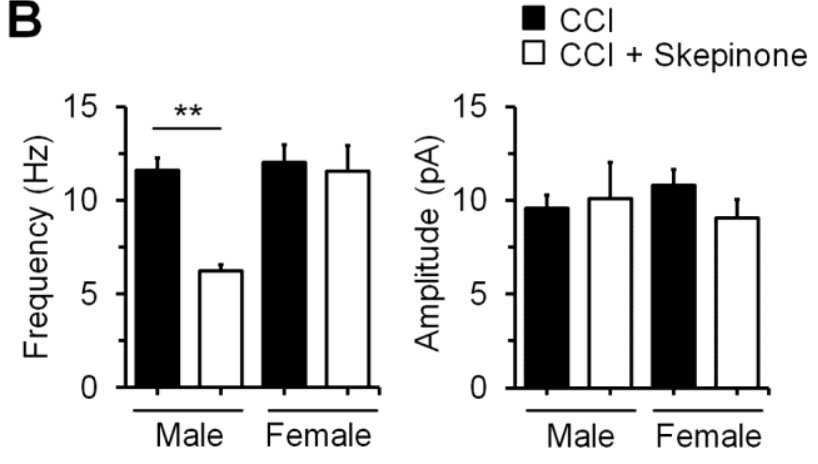